\title{
Friend erythroleukemia cells induce angiogenesis in chick embryo chorioallantoic membrane and in human umbilical vein endothelial cells
}

\author{
STEFANIA PACINI ${ }^{1}$, TIZIANA PUNZI ${ }^{1}$, MASSIMO GULISANO $^{1}$ and \\ MARCO RUGGIERO ${ }^{2}$
}

\author{
${ }^{1}$ Department of Anatomy, Histology and Forensic Medicine; \\ ${ }^{2}$ Department of Experimental Pathology and Oncology, University of Firenze, Italy.
}

\begin{abstract}
The effects of Friend erythroleukemia cells on angiogenesis were studied in chick embryo chorioallantoic membrane assay and in human umbilical vein endothelial cells. In chorioallantoic membrane assay, the conditioned medium of Friend cells stimulated in vivo angiogenesis to an extent comparable to that observed with Prostaglandin E1, used as positive control. Prostaglandin E1 added to conditioned medium of Friend cells did not further increase angiogenesis. Conditioned medium of Friend erythroleukemia cells also stimulated proliferation of human umbilical vein endothelial cells to an extent comparable to that observed with fetal bovine serum, used as positive control. Conditioned medium and fetal bovine serum together did not affect human umbilical vein endothelial cells proliferation, as compared to that observed when tested separately. These results seem to indicate that Friend erythroleukemia cells produce and secrete factors stimulating angiogenesis. These findings extend and confirm the hypothesis that successful angiogenesis is necessary for development of leukemias.
\end{abstract}

Key terms: angiogenesis, chick embryo chorioallantoic membrane assay, Friend erythroleukemia, human endothelial cells

\section{INTRODUCTION}

Angiogenesis is a prerequisite for sustained growth of primary tumors and metastases. Angiogenesis is different from vasculogenesis as this latter is a biologic process by which new blood vessels originate from endothelial cell precursors, whereas in angiogenesis, new blood vessels originate from pre-existing blood vessels (Yancopoulos et al., 1998). Angiogenesis occurs both in physiologic and pathologic conditions, and tumor cells as well as normal growing cells produce and secrete several growth factors and signaling molecules involved in the control of angiogenesis.

Among the signals controlling angiogenesis, prostaglandins play a major role. An example is represented by
Prostaglandin E1 (PGE1), which induces angiogenesis by stimulating transcription of the genes coding for the Vascular Endothelial Growth Factor (VEGF) and of other pro-angiogenic factors, such as basic Fibroblast Growth Factor (bFGF) and Transforming Growth Factor- $\beta$ (TGF- $\beta$ ) and interleukin 6 (IL6) (Francis, 2002).

It has long been known that successful angiogenesis is required for sustained growth of virtually all solid tumors. Recent studies, however, have also demonstrated the importance of angiogenesis in normal hematopoietic cell development as well as in the pathophysiology of several hematologic malignancies including leukemias (Shanafelt and Kay, 2006). Among the different experimental models exploited to investigate leukemias, Friend erythroleukemia cells are 
considered a model system for understanding the physiopathology of human leukemia, the multistage nature of leukemogenesis, and the molecular mechanisms of leukemia resistance (Smadja-Joffe et al., 1975; Ney and D'Andrea, 2000). Nonetheless, the relationship between Friend erythroleukemia and angiogenesis has not yet been studied.

Based upon these assumptions, we studied the angiogenic response induced by Friend erythroleukemia cells in two wellestablished models for angiogenesis investigation, i.e., the chick embryo Chorioallantoic Membrane (CAM) assay and Human Umbilical Vein Endothelial Cells (HUVEC) cultures. Given the fundamental role of prostaglandins in the control of angiogenesis, one of these signaling molecules (PGE1) was used as control. The use of CAM as a model system also allowed discrimination between the observed effects of Friend erythroleukemia cells and of PGE1 on angiogenesis vs vasculogenesis. Thus, observation of the growing embryo allowed the determination of whether the different substances tested affected vasculogenesis, compromising its viability, or selectively affected angiogenesis.

\section{MATERIALS AND METHODS}

Friend erythroleukemia cells (ATCC, Manassas, VA, USA) were routinely maintained in culture medium (Cataldi et al., 2003); briefly, RPMI-1640 medium (Gibco, Milan, Italy) was supplemented with 10\% Fetal Calf Serum (FCS) (Gibco, Milan, Italy) and $1 \%$ penicillin $(10,000 \mathrm{U} /$ $\mathrm{ml}) /$ streptomycin $(10 \mathrm{mg} / \mathrm{ml})$ (Gibco, Milan, Italy), at $37^{\circ} \mathrm{C}$ in a controlled atmosphere with $5 \% \mathrm{CO}_{2}$.

HUVEC (ATCC, Manassas, VA, USA) were routinely maintained in complete culture medium containing: endothelial basal growth medium (EBM-2) with 2\% fetal bovine serum (FBS), $0.4 \%$ human FGF-B, $0.1 \%$ VEGF, $0.1 \%$ recombinant long $\mathrm{R}$ Insulin-like Growth Factor-B $\left(\mathrm{R}^{3}\right.$ IGF-1), 0.1\% human Epidermal Growth Factor (h-EGF), $0.1 \%$ gentamicin sulfate (GA-1000), $0.04 \%$ hydrocortisone, $0.1 \%$ ascorbic acid, and $0.1 \%$ heparin. All these culture medium components were from Cambrex Bio Science, Milan, Italy.

HUVEC were seeded in cell-culture flasks coated with $0.2 \%$ gelatin (Sigma Chemical Co., Milan, Italy), at $37^{\circ} \mathrm{C}$ in a controlled atmosphere with $5 \% \mathrm{CO}_{2}$.

$3 \times 10^{7}$ Friend erythroleukemia cells were placed in $75 \mathrm{~cm}^{2}$ culture flasks without FCS and incubated for $48 \mathrm{~h}$. At the end of incubation, conditioned medium (CM) was collected, sequentially centrifuged at 3,000 and $15,000 \mathrm{~g}$ for $10 \mathrm{~min}$, respectively, and filtered through $0.22 \mu \mathrm{m}$ pore-size filters (Ribatti et al., 1998).

\section{CAM assay}

The CAM is an extra-embryonic membrane, which serves as a gas exchange surface (Romanoff, 1960). Its respiratory function is provided through an extensive capillary network. CAM is formed on the fourth day of incubation by the fusion of the ectodermal epithelium (chorion) and the endodermal epithelium (allantois). At this stage, undifferentiated blood vessels are scattered in the mesoderm of the CAM. They grow very rapidly until day 8 , when some vessels differentiate into capillaries and form a layer at the base of the ectoderm. At day 14, 6 days before hatching, the capillary plexus is located at the surface of the ectoderm, adjacent to the shell membrane (Ausprunk et al., 1974; 1977). The CAM includes the chorioallantoic fluid into which waste products are delivered. Because of its extensive vascularization, CAM has been widely utilized as an in vivo model for the evaluation of angiogenic and antiangiogenic molecules (Wilting et al., 1991; Ribatti et al., 1999).

For the CAM assays, fertilized white Leghorn chicken eggs were incubated under routine conditions (i.e., $60 \%$ relative humidity at $37.5^{\circ} \mathrm{C}$ ), and a square window of approximately $7 \mathrm{~cm}^{2}$ was opened in the egg shell at day 3 of incubation, after removal of $3.5 \mathrm{ml}$ of albumen to detach the shell from the developing CAM. The window was sealed with a glass, and the eggs were returned to the incubator. Gelatin sponges (Upjohn Company, Kalamazoo, 
USA) were cut to a size of less than $1 \mathrm{~mm}^{3}$ and placed on the top of the CAM at day 8 under sterile conditions (Ribatti et al., 1997). The sponges (1/egg) were then soaked with $5 \mu$ l of tested compounds such as Phosphate Buffered Saline (PBS), PGE1 and CM. PGE1 (0.001-10 mg/ml) was used as positive control to induce angiogenesis. $\mathrm{CM}$ was tested at different dilutions (i.e., undiluted or diluted in culture medium at $1: 10,1: 100,1: 1000)$. In each experiment, we used 6 eggs for experimental point (i.e., 6 eggs treated with PBS, 6 eggs treated with PGE1, and so on). Each experiment was repeated 3 times; thus, 18 eggs per experimental point were scored.
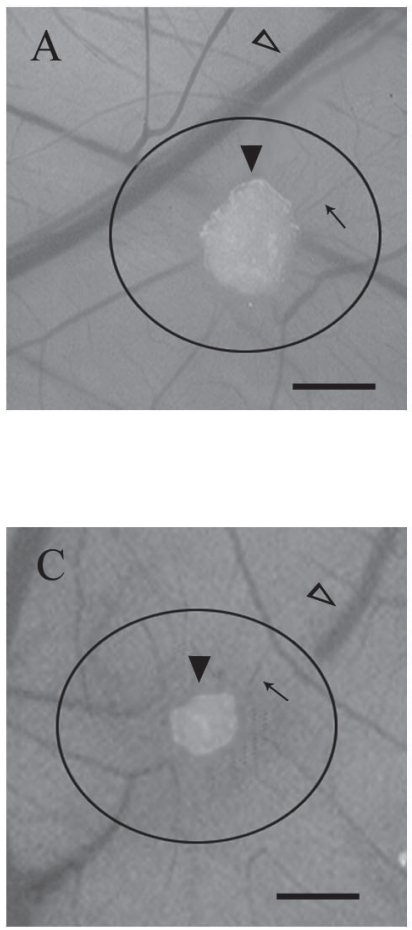

CAMs were examined daily and photographed in ovo at day 12 (Fig. 1). Eggs were examined by stereomicroscopy, and positive angiogenesis was considered if new microvessels (in particular, microvessels surrounding the sponge, defined as circumfocal microvessels) had developed. Live images of the CAM were captured using a high-resolution digital camera connected with the stereomicroscope. Fig. 1 depicts examples of the angiogenic response of the CAM after implantation of gelatin sponges soaked with different substances. In each panel of Fig. 1, we report the picture of a single egg, representative of 18 treated in the same manner.
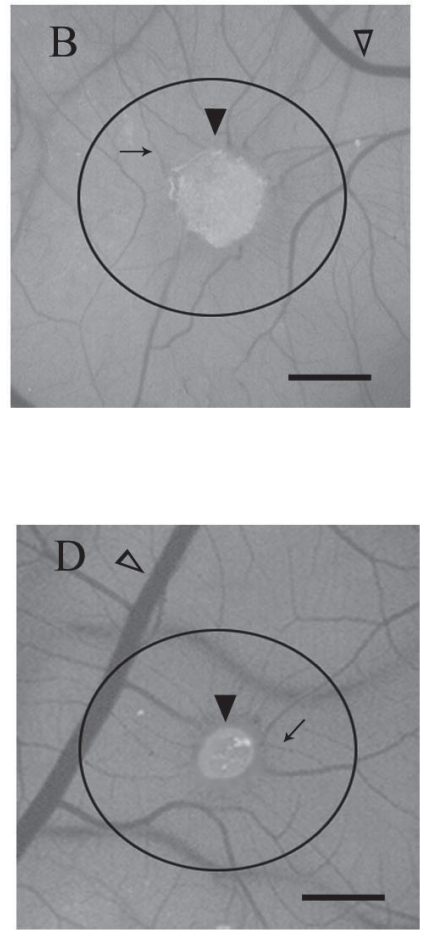

Figure 1: Angiogenic response of the chick embryo Chorioallantoic Membrane (CAM) after implantation of gelatin sponges soaked with different substances.

Panel A: PBS, negative control. A weak vascular reaction was detectable around the sponge.

Panel B: PGE1 $(1 \mathrm{mg} / \mathrm{ml})$, positive control. A strong angiogenic response with numerous allantoic vessels developing radially towards the implant was observed.

Panel C: undiluted CM of Friend erythroleukemia cells. A strong angiogenic response comparable to that induced by PGE1 was detectable.

Panel D: PGE1 $(1 \mathrm{mg} / \mathrm{ml})$ plus undiluted CM of Friend erythroleukemia cells. The angiogenic response was similar to that observed with undiluted CM or PGE1 $(1 \mathrm{mg} / \mathrm{ml})$ alone.

Solid arrowheads indicate the gelatin sponges. Open arrowheads indicate major blood vessels. Solid arrows indicate newly formed, angiogenic blood vessels. Total magnification: x25. Scale bar: 0.4 $\mathrm{mm}$. The circle around each sponge indicates the circumfocal area where microvessels were scored. 
Captured images were digitized and analyzed for the number of angiogenic blood vessels (i.e., those surrounding the sponges), using a customized imageanalysis software program (Scion Corporation, Frederick, MD, USA). Small (diameter $<1 \mathrm{~mm}$ ), large (diameter $>1$ $\mathrm{mm}$ ), and tortuous microvessels were observed at different magnifications.

Angiogenesis was assessed by scoring the Circumfocal Microvessel Number $(\mathrm{CFMN})$, following the procedure recently validated (Sharma et al., 2001). The area surrounding the sponges where CFMN was scored is indicated by a circle in each panel of Fig. 1. Since the CAM is an anatomical structure similar to a disc about $400 \mu \mathrm{m}$ thick, all the angiogenic vessels within the circumfocal area could be scored as if they were on a flat surface (Ribatti et al., 1997; Sharma et al., 2001). Observers (2 for each experiment) were blinded with regard to the experimental conditions.

Quantitative evaluation of angiogenesis, expressed as CFMN, induced by each compound is shown in Table I.

HUVEC proliferation was monitored as incorporation of $\left[{ }^{3} \mathrm{H}\right]$ thymidine in duplicating DNA and measured by liquid scintillation after a $4 \mathrm{~h}$ pulse of $\left[{ }^{3} \mathrm{H}\right]$ thymidine (Love-Schimenti et al., 1996; Pacini et al., 1999). Each experimental point was performed in triplicate samples. At sub-confluence, the medium was changed, and HUVEC were maintained in medium without $2 \% \mathrm{FBS}$, $0.4 \%$ h-FGF-B, $0.1 \%$ VEGF, $0.1 \% \mathrm{R}^{3}$-IGF$1,0.1 \%$ h-EGF, $0.1 \%$ GA-1000 (i.e., EBM2 supplemented with hydrocortisone, ascorbic acid and heparin) for $48 \mathrm{~h}$. Afterward, the cells were challenged for 24 h with PBS or FBS (10\%) or undiluted CM Friend erythroleukemia cells or undiluted CM Friend erythroleukemia cells plus FBS $(10 \%)$. For the dose-dependence curve, the endothelial cell medium was replaced with different dilutions of CM (i.e., undiluted or diluted at $1: 10,1: 100,1: 1000)$; for the time-dependence curve, cells were pulselabeled with $\left[{ }^{3} \mathrm{H}\right]$ thymidine after 24,48 , and $72 \mathrm{~h}$ stimulation as described (LoveSchimenti et al., 1996). In both cases, ${ }^{3}[\mathrm{H}]$ radioactivity was measured as count per minute $(\mathrm{cpm})$ by liquid scintillation counting.

Differences between continuous variables were examined by Student's $t$ test. Differences were considered statistically significant when $\mathrm{p}<0.02$.

\section{RESULTS AND DISCUSSION}

Friend erythroleukemia is considered a model system for the understanding of multistage carcinogenesis (Ney and D'Andrea, 2000) and tumor progression (Tambourin et al., 1991). Since both processes require successful angiogenesis (Bergers et al., 1999; Moehler et al., 2003;

TABLE I

Chick embryo Chorioallantoic Membrane (CAM) assay

\begin{tabular}{lccc}
\hline & CFMN & S.E.M. & $\%$ \\
\hline PBS & 20.2 & 0.47 & 100 \\
PGE1 & $34.0^{*}$ & 0.99 & 168 \\
Undiluted CM Friend erythroleukemia cells & $37.5^{*}$ & 0.92 & 186 \\
Undiluted CM Friend erythroleukemia cells + PGE1 & $34.7^{*}$ & 0.61 & 172 \\
\hline
\end{tabular}

The number of angiogenic blood vessels, expressed as CFMN, derived from scoring small (diameter $<1 \mathrm{~mm}$ ), large (diameter $>1 \mathrm{~mm}$ ), and tortuous microvessels is reported for each experimental point. Undiluted CM of Friend erythroleukemia cells was prepared as described in the Materials and Methods section. Data are reported as means \pm S.E.M. $(n=18)$. * indicates significant difference from PBS $(\mathrm{p}<0.02)$. 
Moheler et al., 2004; Molica et al., 2004), first we tested the angiogenic effect of $\mathrm{CM}$ from Friend erythroleukemia cells in the CAM assay (Table I and Fig. 1). Angiogenic response could be quantitatively scored as described in the Materials and Methods section.

In the specimens treated with PBS as negative control, only a weak vascular reaction was detectable around the sponges (Table I and Fig. 1A). PGE1, a known stimulator of angiogenesis, elicited a dosedependent response of the developing vasculature of the CAM (Fig. 2). Fig. 1B shows the effects of PGE1 at $1 \mathrm{mg} / \mathrm{ml}$ concentration, i.e., a concentration that elicited maximal response: blood vessels with an irregular course and frequent branching were observed; the gelatin sponges were surrounded by allantoic vessels that developed radially towards the implant in a radial pattern.

Undiluted CM of Friend erythroleukemia cells stimulated angiogenesis to an extent comparable to the maximal effect achieved by PGE1 (Table I, Fig. 1C). The stimulatory effect of $\mathrm{CM}$ was concentration-dependent, as shown in Fig. 3, reporting data from experiments where different dilutions of $\mathrm{CM}$ were tested. These results could be explained considering that Friend erythroleukemia cells may produce and secrete growth factors stimulating angiogenesis in analogy to what observed in other leukemic cell types (Ruan et al., 2001; Ebos et al., 2002). PGE1 (1 mg/ $\mathrm{ml}$ ) added to the undiluted CM of Friend erythroleukemia cells did not significantly increase angiogenesis (Table I and Fig. 1D), as if maximal response in the CAM assay had been reached.

The results observed in the CAM assay were replicated in another experimental model widely used in studying angiogenesis, i.e., proliferation in HUVEC measured as $\left[{ }^{3} \mathrm{H}\right]$ thymidine incorporation (Table II). HUVEC treatment with PBS and FBS as negative and positive control, respectively, and with undiluted CM of Friend erythroleukemia cells, was analogous to that described in the CAM assay. 10\% FBS

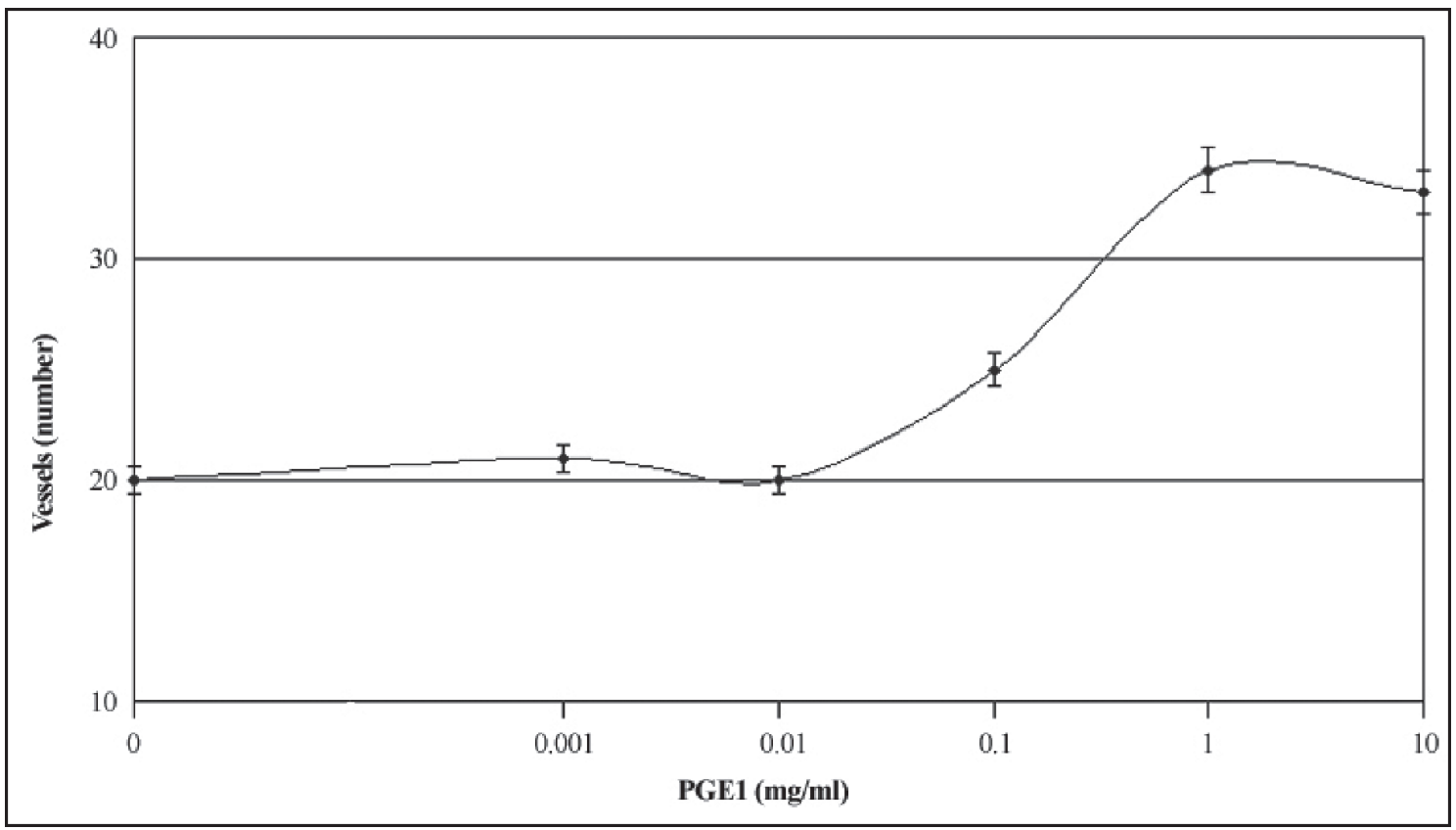

Figure 2: PGE1-induced angiogenesis in the chick embryo Chorioallantoic Membrane (CAM) assay.

The number of angiogenic blood vessels derived from scoring small (diameter $<1 \mathrm{~mm}$ ), large (diameter $>1 \mathrm{~mm}$ ), and tortuous microvessels is reported for each experimental point. Data are reported as means \pm S.E.M. $(n=18)$. 
stimulated HUVEC proliferation (Table II) to an extent similar to that observed studying angiogenesis in the CAM assay after stimulation with PGE1 (Table I). Undiluted $\mathrm{CM}$ of Friend erythroleukemia cells induced a strong HUVEC proliferation. The effect of $\mathrm{CM}$ was dose- and time-dependent (Fig. 4A and B) and comparable to that induced by positive control (Table II). Overall, these results were consistent with those observed in the CAM assay after undiluted CM stimulation (Table I). Just as observed in the CAM assay, undiluted CM added to positive control (FBS) did not significantly increase HUVEC proliferation as compared to the proliferative effects induced by undiluted $\mathrm{CM}$ and positive control tested separately (Table II).

In this study, we demonstrate that CM of Friend erythroleukemia cells stimulated HUVEC proliferation and angiogenesis in chick embryo. Friend erythroleukemia cells, similar to several other transformed cell types, may produce and secrete growth factors stimulating angiogenesis and proliferation of endothelial cells (Ruan et al., 2001; Ebos et al., 2002). To our knowledge, this is the first observation concerning Friend erythroleukemia cells and angiogenesis.

In addition, the observed normal development of the embryo suggests that $\mathrm{CM}$ of Friend erythroleukemia cells did not alter the process of vasculogenesis. Indeed, vasculogenesis is a biological process occurring during embryo development in which new blood vessels originate from endothelial cell precursors, and it is unlike angiogenesis, in which new blood vessels originate from pre-existing blood vessels (Yancopoulos et al., 1998). Successful vasculogenesis is essential for normal embryo development and viability (Flamme et al., 1997).

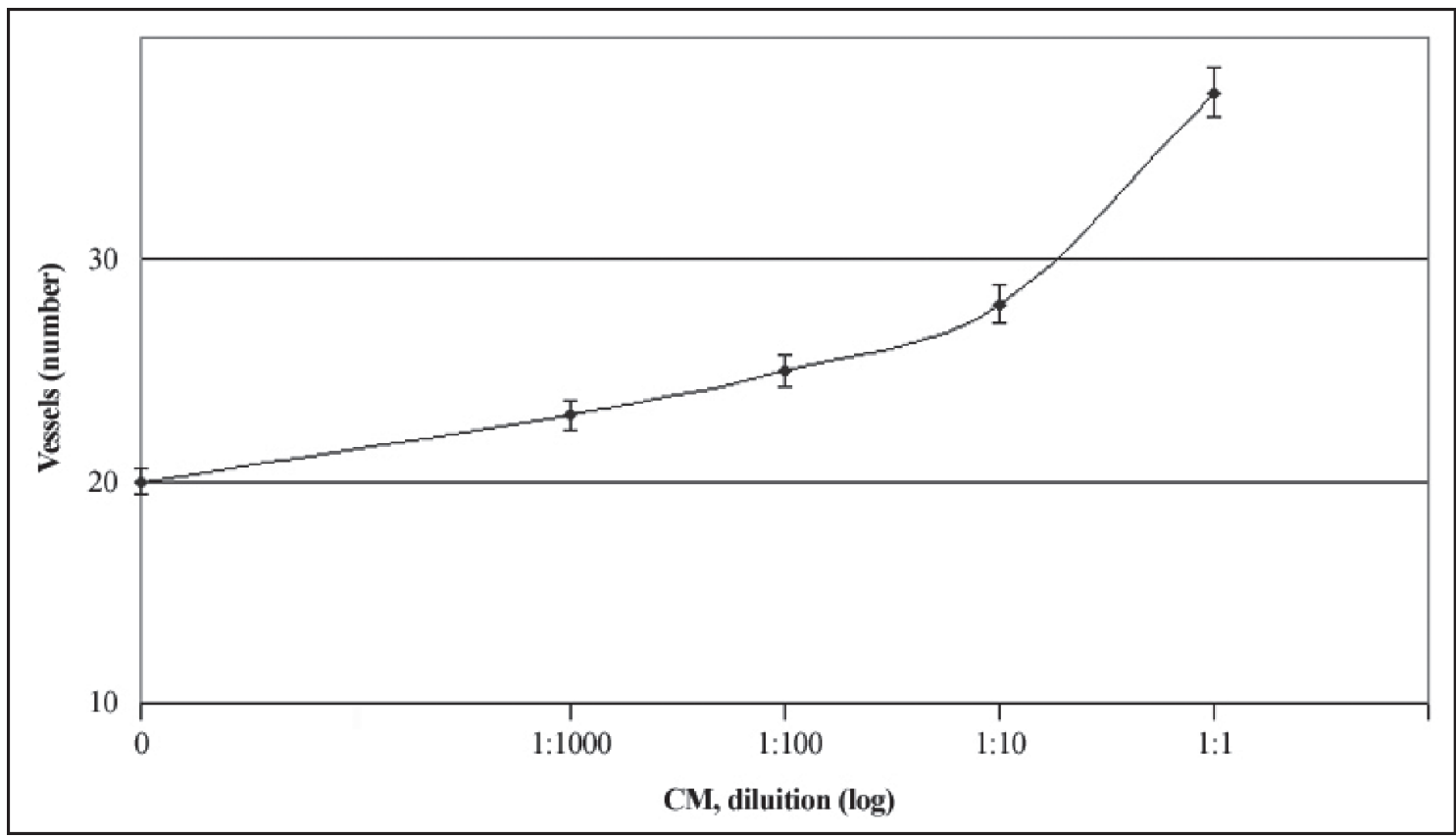

Figure 3: CM-induced angiogenesis in the chick embryo Chorioallantoic Membrane (CAM) assay. $\mathrm{CM}$ of Friend erythroleukemia cells was added at the dilution indicated in the horizontal axis. 0 indicates the absence of CM; 1:1 indicates undiluted CM. The number of angiogenic blood vessels (vertical axis) derived from scoring small (diameter $<1 \mathrm{~mm}$ ), large (diameter $>1 \mathrm{~mm}$ ), and tortuous microvessels is reported for each experimental point. Data are reported as means \pm S.E.M. $(n=18)$. 


\section{Panel A}

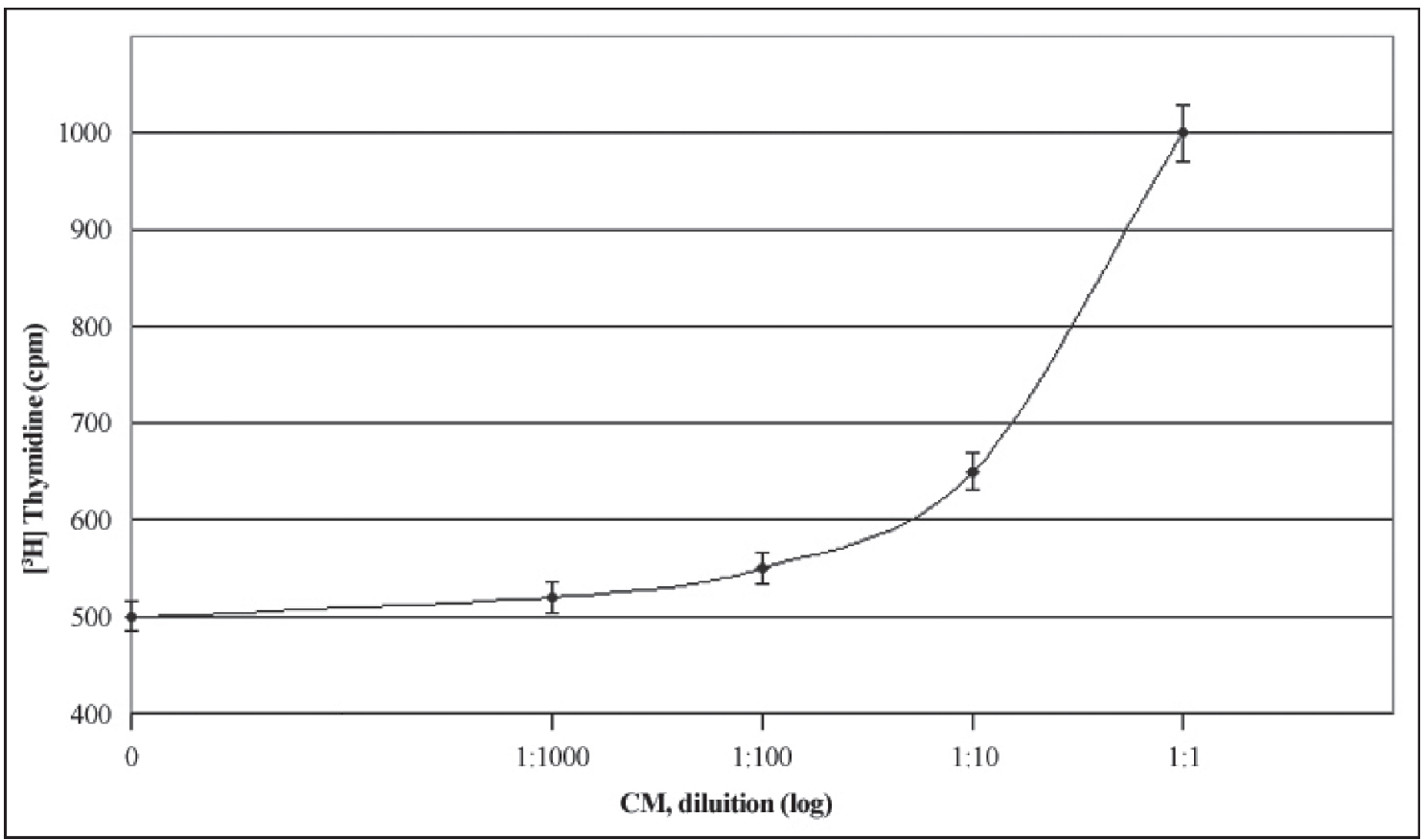

\section{Panel B}

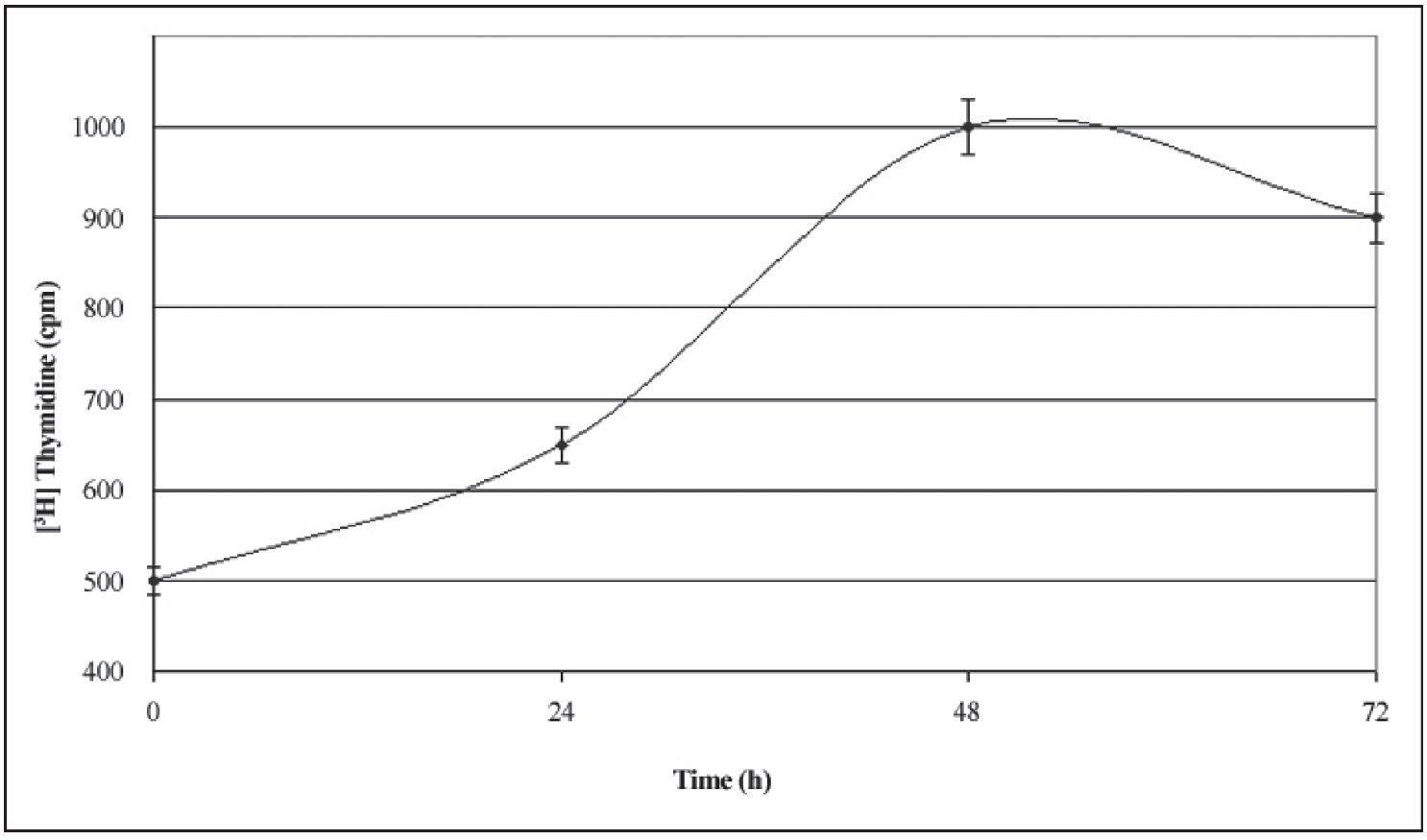

Figure 4: Human Umbilical Vein Endothelial Cells (HUVEC) proliferation.

HUVECs were challenged with CM of Friend erythroleukemia cells at the dilution indicated in the horizontal axis (Panel A). 0 indicates the absence of CM; 1:1 indicates undiluted CM. Undiluted $\mathrm{CM}$ was tested for different time intervals as indicated in Panel B. HUVEC proliferation was assessed by measuring incorporation of $\left[{ }^{3} \mathrm{H}\right]$ thymidine in duplicating DNA by liquid scintillation after a $4 \mathrm{~h}$ pulse of $\left[{ }^{3} \mathrm{H}\right]$ thymidine. Each point (cpm, as indicated in the vertical axis) represents the means of triplicate samples + S.E.M. 
TABLE II

Human Umbilical Vein Endothelial Cells (HUVEC) proliferation study

\begin{tabular}{lccc}
\hline & Cpm & S.E.M. & $\%$ \\
\hline PBS & 550 & 20 & 100 \\
FBS & $1081^{*}$ & 180 & 196 \\
Undiluted CM Friend erythroleukemia cells & $1005^{*}$ & 193 & 183 \\
Undiluted CM Friend erythroleukemia cells + FBS & $1038^{*}$ & 185 & 189 \\
\hline
\end{tabular}

HUVECs after $48 \mathrm{~h}$ starvation were challenged for $24 \mathrm{~h}$ with PBS or FBS. In the experiments in which undiluted $\mathrm{CM}$ of Friend erythroleukemia cells were tested, the endothelial cell medium was completely replaced with undiluted $\mathrm{CM}$ or with undiluted CM plus FBS. HUVEC proliferation was assessed by measuring incorporation of $\left[{ }^{3} \mathrm{H}\right]$ thymidine in duplicating DNA by liquid scintillation after a $4 \mathrm{~h}$ pulse of $\left[{ }^{3} \mathrm{H}\right]$ thymidine. Each point represents the mean of triplicates + S.E.M. * indicates significant difference from $\operatorname{PBS}(\mathrm{p}<0.02)$.

The absence of harmful side effects on chick embryo development and viability observed in our study demonstrates that physiological vasculogenesis of developing embryos was unaffected by $\mathrm{CM}$ of Friend erythroleukemia cells. The observed selectivity of effect (i.e., stimulation of angiogenesis without affecting physiological vasculogenesis of developing embryos) holds great promise for development of therapeutic candidates that could selectively target leukemia-associated angiogenesis. This could be important because, beside its role during development, vasculogenesis contributes to the formation of new blood vessels in adults after tissue ischemia (Walter and Dimmeler, 2002), and its inhibition would be harmful, in particular for patients with concurring ischemic diseases.

\section{ACKNOWLEDGEMENTS}

This study was supported by grants from the University of Firenze, Italy. S.P. and M.R. also received a grant from the Italian Foundation of Cancer Research. We are indebted to Prof. Persio dello Sbarba and Dr. Lucia Magnelli for critical discussion. We are thankful to Sara Quagliata for technical help and for helpful suggestions.

\section{REFERENCES}

AUSPRUNK D, KNIGHTON D, FOLKMAN J (1974) Differentiation and vascular endothelium in the chick chorioallantois: A structural and autoradiographic study. Dev Biol 38: 237-249

AUSPRUNK D, KNIGHTON D, FOLKMAN J (1977) Vascularization of normal and neoplastic tissues grafted to the chick chorioallantois. Am J Pathol 79: 597-618

BERGERS G, JAVAHERIAN K, LO KM, FOLKMAN J, HANAHAN D (1999) Effects of angiogenesis inhibitors on multistage carcinogenesis in mice. Science 284: 808-812

CATALDI A, DI PIETRO R, CENTURIONE L, RAPINO $\mathrm{M}$, SANTA VENERE E, GARACI F, COCCO L, GIULIANI-PICCARI G, RANA R (2003) Engagement of PI-3-kinase-mediated protein kinase $\mathrm{C}$ z activation in protecting Friend cells from ionizing radiationinduced apoptosis. Int J Oncol 22: 129-135

EBOS JM, TRAN J, MASTER Z, DUMONT D, MELO JV, BUCHDUNGER E, KERBEL RS (2002) Imatinib mesylate (STI-571) reduces Bcr-Abl-mediated vascular endothelial growth factor secretion in chronic myelogenous leukemia. Mol Cancer Res 1: 89-95

FLAMME I, FROLICH T, RISAU W (1997) Molecular mechanisms of vasculogenesis and embryonic angiogenesis. J Cell Physiol 173: 206-210

FRANCIS JG (2002) The emerging role of angiogenesis inhibitors in hematological malignancies. Oncology 16: 23-29

LOVE-SCHIMENTI CD, GIBSON DFC, RATMAN AV, BIKLE DD (1996) Antiestrogen potentiation of antiproliferative effects of Vitamin D3 analogues in breast cancer cells. Cancer Res 56: 2789-2794

MOEHLER TM, HO AD, GOLDSCHMIDT H, BARLOGIE B (2003) Angiogenesis in hematological malignancies. Crit Rev Oncol Hematol 45: 227-244

MOEHLER TM, HILLENGASS J, GOLDSCHMIDT H, HO AD (2004) Antiangiogenic therapy in hematologic malignancies. Curr Pharm Des 10: 1221-1234 
MOLICA S, VACCA A, LEVATO D, MERCHIONNE F, RIBATTI D (2004) Angiogenesis in acute and chronic lymphocytic leucemia. Leuk Res 28: 321-324

NEY PA, D'ANDREA AD (2000) Friend erythroleukemia revisited. Blood 96: 3675-3680

PACINI S, ATERINI S, PACINI P, RUGGIERO C, GULISANO M, RUGGIERO M (1999) Influence of static magnetic field on the antiproliferative effects of vitamin D on human breast cancer cells. Oncol Res 11: 265-271

RIBATTI D, GUALANDRIS A, BASTAKI M, VACCA A, IURLARO M, RONCALI L, PRESTA M (1997) New model for the study of angiogenesis and antiangiogenesis in the chick embryo chorioallantoic membrane: The gelatin sponge/chorioallantoic membrane assay. J Vasc Res 34: 455-463

RIBATTI D, ALESSANDRI G, VACCA A, IURLARO M, PONZONI M (1998) Human neuroblastoma cells produce extracellular matrix-degrading enzymes, induce endothelial cell proliferation and are angiogenic in vivo. Int J Cancer 77: 449-454

RIBATTI D, GUALANDRIS A, BELLERI M, MASSARDI L, NICO B, RUSNATI M, DELL'ERA P, VACCA A, RONCALI L, PRESTA M (1999) Alterations of blood vessel development by endothelial cells overexpressing fibroblast growth factor 2. J Pathol 18: 6240-6248

ROMANOFF AL (1960) The extraembryonic membranes. In: The avian embryo: Structural and functional development. New York: MacMillan, pp.1039-1041

RUAN GR, LIU YR, CHEN SS, LI JL, QIN YZ, FU JY, BAI RK (2001) Expression of vascular endothelial growth factor in the bone marrow cells from adult chronic myelogenous leukemia. Zhongguo Shi Yan Xue Ye Xue Za Zhi 9: 5-9

SHANAFELT TD, KAY NE (2006) The clinical and biologic importance of neovascularization and angiogenic signaling pathways in chronic lymphocytic leukemia. Semin Oncol 33: 174-185

SHARMA S, GHODDOUSSI M, GAO P, KELLOFF GJ, STEELE VE, KOPELOVICH L (2001) A quantitative angiogenesis model for efficacy testing of chemopreventive agents. Anticancer Res 21: 38293837

SMADJA-JOFFE F, JASMIN C, KERDILES C, KLEIN B (1975) Friend leukemia: A model for the physiopathology of human leukemia. Eur J Cancer 11: 831-840.

TAMBOURIN P, WENLING F, MOREAU-GACHELIN F (1991) Friend leukemia as a multiple-step disease. Blood cells 7: 133-144

YANCOPOULOS GD, KLAGSBRUN M, FOLKMAN J (1998) Vasculogenesis, angiogenesis and growth factors: Ephrins enter the fray at the border. Cell 93: 661-664

WALTER DH, DIMMELER S (2002) Endothelial progenitor cells: Regulation and contribution to adult neovascularisation. Hertz 27: 579-588

WILTING J, CHRIST B, BOKELOH MA (1991) Modified chorioallantoic membrane (CAM) assay for qualitative and quantitative study of growth factors. Anat Embryol 183: $259-271$ 
